\title{
Lessons learned from the 2009-2010 H1N1 pandemic
}

Attendance in ATS May, 2009 in San Diego was lower than expected. That was because in late March 2009, an outbreak of H1N1 influenza A virus infection was detected in Mexico with subsequent cases observed in many other countries including the United States. ${ }^{[1]}$

In Syria, since April, measures were taken in compliance with the World Health Organization policies. Diagnostic tools, treatments and isolation equipments were made available in special hospitals and medical centers.

In May 2009, a joint nationwide educational campaign was launched. Leaders from the local Syrian American Medical Association (SAMA), WHO, and government agencies established an H1N1 influenza pandemic task force for education and training.

Training courses for a large number of health care workers including intensive care units (ICU) physicians and nurses were conducted over wide geographic areas within the country. It was a hard task to do. We had to go back to the basics touching so many areas that were overlooked by the health care system over the years.

As the Head of SAMA, and an academic trainer, I thought that was the most challenging national task I have ever faced.

We were watching the world and learning from others' experience. In June 2009, the World Health Organization (WHO) raised its pandemic alert level to the highest level, phase 6 , indicating widespread community transmission on at least two continents. ${ }^{[2]}$ The pandemic was declared to be over in August 2010.

This pandemic was caused by $\mathrm{H} 1 \mathrm{~N} 1$ influenza A virus that represents a quadruple reassortment of two swine strains, one human strain, and one avian strain of influenza; the largest proportion of genes came from swine influenza virus.

Obviously, we learned that this was not the first "swine flu" in human history. Illness with influenza in pigs was first recognized during the influenza pandemic of 1918 to 1919 , and a swine influenza virus was first isolated from a human in 1974, and caused the first fatality in New Jersey in $1976 .{ }^{[3]}$
Between 1958 and 2005, 37 cases of swine influenza were reported. Six (17 percent) resulted in death. Forty-four percent of infected individuals had known exposure to pigs.

During this pandemic, over 99 percent of subtyped influenza A isolates in Europe and the United States were pandemic H1N1 influenza A. ${ }^{[4]}$

In September 2010, one group estimated that approximately 59 percent of the United States population is immune to pandemic H1N1 influenza A, from natural infection, immunization, or pre-existing immunity that developed following remote infection with related strains.

In contrast to previous outbreaks of prior swine influenza viruses, this pandemic demonstrated sustained human-tohuman transmission. ${ }^{[5]}$

Transmission in households occurred in 13 percent of persons. Contacts who were 18 years of age or younger were most susceptible, whereas individuals older than 50 years were significantly less susceptible.

We also learned that pandemic comes in waves. After the first wave of pandemic in the spring of 2009 a second wave in the subsequent fall followed after schools opened. We stayed on the alert until the Pandemic was declared over.

During the crisis, we stopped confirming cases by laboratory tests, as the number of outpatient cases was overwhelming. Confirmation was left only for cases with expected high mortality rate in the ICUs. We recognized that more than 213 more countries and territories reported laboratoryconfirmed cases, but estimated actual cases may have been up to 140 times greater ${ }^{[6]}$ So, since early July 2009 , the WHO itself ceased closely tracking the number of cases.

We noticed an alarming high mortality rate in the ICU's, especially outside the Capital "Damascus". But, the actual number of community cases, hospitalizations and fatality rate in other cities were not known. If we extrapolate from other reliable sources, we find that in the United States, Centers for Disease Control and Prevention (CDC) estimated that between April 2009 and April 10, 2010, approximately 61 million cases of pandemic H1N1 influenza occurred in the United States, including approximately 274,000 hospitalizations, and 12,470 deaths. ${ }^{[7]}$ By extrapolation, 
expected number of cases, hospitalization and death rate in Syria could be 4.5 million, 21,000 and 950 respectively.

The authors of this paper ${ }^{[8]}$ shed some light on the most severe cases admitted to 4 major hospitals in Damascus. The high mortality rate was disturbing, so was the level of preparation and readiness to deal with such an enormous national health crisis. Had we not done so much beforehand, numbers would have been expected to be much worse. Outside the capital, unpublished data indicate that much more needs to be done.

Despite the enormous efforts made to fight the pandemic, the excellent basic heath infrastructure and the advanced medical technology, major gaps were overlooked and were much needed to effectively deal with the crisis. One crucial area that had major negative impact was the serious lack of adequate number of specialists in ICU, infection control and infectious diseases.

Unfortunately, serious negative outcome might have been easily overlooked in the absence of accurate surveillance data.

More lessons were learned from the world:

- Although mortality rate in the United States $(0.12$ deaths per 100,000 population) was lower than the number of deaths caused by seasonal influenza during non-pandemic years, the number of years of life lost was substantial since the pandemic affected younger individuals disproportionately. ${ }^{[9]}$

- Hospitalization was required in 2-5 percent of confirmed cases. Thirty one percent of hospitalized cases were admitted to the intensive care unit and 11 percent died.

- Mortality was relatively high among individuals $<65$ years of age and relatively low among those $\geq 65$ years of age.

- Most deaths were related to respiratory failure resulting from severe pneumonia with multifocal infiltrates and acute respiratory distress syndrome.

- Among hospitalized patients, those who died presented for hospitalization later (median 3 versus 2 days) and received oseltamivir later (median 6.5 versus 3 days) than those who survived. ${ }^{[10]}$

- The majority of reported deaths occurred in individuals with underlying health problems. ${ }^{[1]}$

- The most common risk factors for influenza complications were chronic lung disease (37 percent), immunosuppressive conditions (17 percent), cardiac disease (17 percent), pregnancy (17 percent), diabetes mellitus (13 percent), and obesity (13 percent). A history of asthma was also overrepresented among both children and adults. ${ }^{[12]}$

Naem Shahrour

Pulmonary Department, Damascus University, Damascus, Syria E-mail: sj.center@gmail.com

\section{REFERENCES}

1. Centers for Disease Control and Prevention (CDC). Outbreak of swineorigin influenza A (H1N1) virus infection - Mexico, March-April 2009. MMWR Morb Mortal Wkly Rep 2009;58:467-70.

2. World Health Organization. World now at the start of 2009 influenza pandemic. Available from: http://www.who.int/mediacentre/news/ statements/2009/h1n1_pandemic_phase6_20090611/en/index.html. [Last Accessed on 2009 Jun 11].

3. Gaydos JC, Hodder RA, Top FH Jr, Russell PK. Swine influenza A at Fort Dix, New Jersey (January-February 1976). I. Case fin. Emerg Infect Dis 2006;12:23-8.

4. World Health Organization. Pandemic (H1N1) 2009 - update 86. Available from: http://www.who.int/csr/don/2010_02_5/en/index.html. [Last Accessed on 2010 Feb 9].

5. Reed C, Angulo FJ, Swerdlow DL, Lipsitch M, Meltzer MI, Jernigan D, et al. Estimates of the prevalence of pandemic (H1N1) 2009, United States, April-July 2009. Emerg Infect Dis 2009;15:2004-7.

6. Shrestha SS, Swerdlow DL, Borse RH, Prabhu VS, Finelli L, Atkins C, et al. Estimating the burden of 2009 pandemic influenza A (H1N1) in the United States (April 2009-April 2010). Clin Infect Dis 2011;52 Suppl 1:S75-82.

7. United States Centers for Disease Control and Prevention. Interim CDC guidance for nonpharmaceutical community mitigation in response to human infections with swine influenza (H1N1) virus. Available from: http://www.cdc.gov/swineflu/mitigation.htm. [Last Accessed on 2011 Oct 14].

8. Kherallah M. Characteristics and Outcome of Critically Ill Patients with 2009 H1N1 Influenza A Infection in Syria. Avicenna J Med 2012;2:.

9. Viboud C, Miller M, Olson D, Osterholm M, Simonsen L. Preliminary estimates of mortality and years of life lost associated with the $2009 \mathrm{~A} /$ H1N1 pandemic in the US and comparison with past influenza seasons. PLoS Curr 2010:RRN1153.

10. Skarbinski J, Jain S, Bramley A, Lee EJ, Huang J, Kirschke D, et al. Hospitalized patients with 2009 pandemic influenza A (H1N1) virus infection in the United States--September-October 2009. Clin Infect Dis 2011;52 Suppl 1:S50-9.

11. Lee EH, Wu C, Lee EU, Stoute A, Hanson H, Cook HA, et al. Fatalities associated with the 2009 H1N1 influenza A virus in New York city. Clin Infect Dis 2010;50:1498-504.

12. O'Riordan S, Barton M, Yau Y, Read SE, Allen U, Tran D, et al. Risk factors and outcomes among children admitted to hospital with pandemic H1N1 influenza. CMAJ 2010;182:39-44.

\begin{tabular}{|l|l|}
\hline \multicolumn{2}{|c|}{ Access this article online } \\
\hline Quick Response Code: \\
\hline
\end{tabular}

